\title{
Metabolic Stress Induces Caspase-3 Mediated Degradation and Inactivation of Farnesyl and Geranylgeranyl Transferase Activities in Pancreatic $\beta$-Cells
}

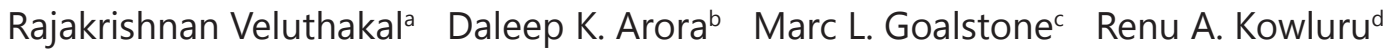 \\ Anjaneyulu Kowlurue,f \\ aDepartment of Molecular and Cellular Endocrinology, Diabetes and Metabolic Research Institute, City \\ of Hope/BRI, Duarte, bepartment of Microbiology and Immunology, University of Oklahoma Health \\ Sciences Center, Oklahoma City, 'Research Service, VA Medical Center, and Division of Endocrinology, \\ Metabolism and Diabetes, University of Colorado School of Medicine, Denver, dDepartments of \\ Anatomy and Cell Biology and Ophthalmology and ePharmaceutical Sciences, Wayne State University, \\ Detroit, ${ }^{\dagger} \beta$-Cell Biochemistry Laboratory, John D. Dingell VA Medical Center, Detroit, USA
}

\section{Key Words}

Metabolic stress • Islet $\beta$-cell • Farnesylation • Geranylgeranylation • G-proteins

\begin{abstract}
Background/Aims: At least 300 prenylated proteins are identified in the human genome; the majority of which partake in a variety of cellular processes including growth, differentiation, cytoskeletal organization/dynamics and vesicle trafficking. Aberrant prenylation of proteins is implicated in human pathologies including cancer; neurodegenerative diseases, retinitis pigmentosa, and premature ageing syndromes. Original observations from our laboratory have demonstrated that prenylation of proteins [small G-proteins and $\gamma$-subunits of trimeric G-proteins] is requisite for physiological insulin secretion. Herein, we assessed the impact of metabolic stress [gluco-, lipotoxicity and ER-stress] on the functional status of protein prenylation pathway in pancreatic $\beta$-cells. Methods: Farnesyltransferase [FTase] and geranylgeranyltransferase [GGTase] activities were quantified by radioisotopic methods. Caspase-3 activation and FTase/GGTase- $\alpha$ subunit degradation were determined by Western blotting. Results: We observed that metabolic stress activates caspase- 3 and induces degradation of the common $\alpha$-subunit of FTase and GGTase-I in INS-1 832/13 cells, normal rodent islets and human islets leading to functional defects [inactivation] in FTase and GGTase activities. Caspase- 3 activation and FTase/GGTase- $\alpha$ degradation were also seen in islets from the Zucker diabetic fatty [ZDF] rat, a model for Type 2 diabetes. Consequential to defects in FTase/GGTase- $\alpha$ signaling, we observed significant accumulation of unprenylated proteins [Rap1] in $\beta$-cells exposed to glucotoxic conditions. These findings were replicated in $\beta$-cells

R. Veluthakal, D. K. Arora and M. L. Goalstone contributed equally to this work.

Anjaneyulu Kowluru, Ph.D.

B-4237 Research Service, John D. Dingell VA Medical Center, 4646 John R, Detroit, MI 48201, (USA)

Tel. +1 313-576-4478, Fax + 1313-576-1112, E-Mail akowluru@med.wayne.edu
\end{abstract}

KARGER 


\section{Cellular Physiology Cell Physiol Biochem 2016;39:2110-2120

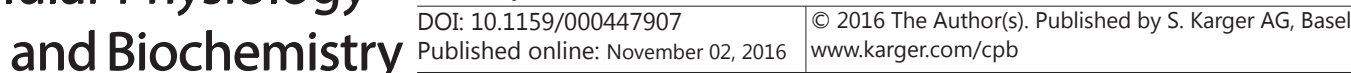 \\ Veluthakal et al.: Metabolic Stress Inactivates Prenyltransferases in Islet $\beta$-Cells}

following pharmacological inhibition of generation of prenylpyrophosphate substrates [Simvastatin] or catalytic activity of prenylating enzymes [GGTI-2147]. Conclusions: Our findings provide the first evidence to suggest that metabolic stress induced dysfunction of the islet $\beta$-cell may, in part, be due to defective protein prenylation signaling pathway.

(C) 2016 The Author(s)

Published by S. Karger AG, Basel

\section{Introduction}

A variety of signaling proteins including small molecular mass G-proteins [e.g., Ras, Cdc42 and Rac1], the $\gamma$-subunits of hetero-trimeric G-proteins and nuclear lamins [e.g., lamins A and B] undergo a series of post-translational modifications at their $\mathrm{C}$-terminal cysteine residues including prenylation [i.e., farnesylation and geranylgeranylation], carboxylmethylation, and palmitoylation [1-7]. It has been demonstrated that such modification steps are requisite for the trafficking/targeting of prenylated proteins to appropriate cellular compartments for optimal interaction with, and activation of, their effector proteins leading to cellular activation [1-7]. Prenylation represents the first modification step in which either a 15-carbon [farnesyl] or a 20-carbon [geranylgeranyl] derivative of mevalonic acid [MVA] is incorporated into candidate proteins (Fig. 1). The farnesyl transferase [FTase] and the geranylgeranyl transferase-1 [GGTase-1] mediate incorporation of farnesylpyrophosphate [Fpp] and geranylgeranyl-pyrophosphate [GGpp], respectively. Examples of farnesylated proteins include $\mathrm{H}$-Ras, lamins $\mathrm{A}$ and $\mathrm{B}$ and geranylgeranylated proteins include small G-proteins such as Cdc42, Rac1, Rho and Rap1 (Fig. 1). FTase and GGTases are heterodimeric comprising of a common $\alpha$-subunit, but distinct $\beta$-subunits, and the latter confer the substrate specificity for FTase and GGTases. Using various small molecule inhibitors of FTase [FTI277] and GGTases [GGTI-2147], or the dominant negative mutant of the FTase/GGTase- $\alpha$ subunit or siRNAs for FTase or GGTase $\beta$-subunits, several recent studies have demonstrated novel roles of protein prenylation in glucose-stimulated insulin secretion [GSIS] from clonal $\beta$-cells and rodent islets [1, 2, 5, 6, 8-11]. In addition to GGTase-I, GGpp is utilized by GGTase-II for geranylgeranylation of Rab subfamily of GTPases (Rab3A; Fig. 1). Note that $\alpha$ and $\beta$ subunits of heterodimeric GGTase-II are distinct from their GGTase-I counterparts. Using pharmacological approaches, we have recently reported key roles for GGTase-II [Rab prenylation] in GSIS [12].

Despite compelling evidence for key regulatory roles of protein farnesylation and geranylgeranylation in islet function, including GSIS, very little is known, however, about the fate of these signaling steps under conditions of metabolic stress in the pancreatic islet $\beta$-cell. In the context of prenyltransferase-mediated regulation of cellular function, Kim and associates have reported that the common $\alpha$-subunit of FTase/GGTase undergoes caspase- 3 mediated cleavage into a smaller peptide [ $\sim 35 \mathrm{kDa}$ ] during cell apoptosis [13]. They reported caspase- 3 activation and FTase/GGTase $\alpha$-subunit degradation in a mouse lymphoma W4 cells [expressing the Fas receptor] following exposure to anti-Fas antibodies. They also observed caspase- 3 activation and FTase/GGTase $\alpha$-subunit degradation in Rat-2/H-ras cells treated with an FTase inhibitor [LB42708] or in Rat-1 cells treated with etoposide, a genotoxic agent. These data have led the authors to suggest key roles for caspase- 3 mediated degradation of FTase/GGTase $\alpha$-subunit in cell demise [13].

More recently, we have assessed the status of FTase/GGTase- $\alpha$ signaling pathway in pancreatic $\beta$-cells exposed to etoposide, which induces robust activation of caspase- 3 and apoptosis in insulin-secreting INS-1 832/13 cells [14]. We demonstrated a marked increase in caspase- 3 activation and FTase/GGTase- $\alpha$ degradation in cells exposed to etoposide. Specificity of caspase- 3 in the degradation of FTase/GGTase- $\alpha$ was further confirmed by pharmacological inhibition of caspase-3 [Z-DEVD-FMK], which prevented etoposide-induced degradation of FTase/GGTase- $\alpha$ in INS-1 832/13 cells. Lastly, degradation of FTase/GGTase- $\alpha$ was also seen in these cells exposed to the active fragment [recombinant] of caspase-3. Based 
Fig. 1. Schematic representation of cholesterol biosynthetic/protein prenylation pathway. HMG-CoA reductase catalyzes the conversion of HMGCoA to mevalonate, which is the precursor for the biosynthesis of Fpp and GGpp. In the presence of Fpp, FTase mediates farnesylation of nuclear lamins ( $A$ and $B$ ), Ras and $\gamma$-subunits of trimeric G-proteins. GGTase-I geranylgeranylates $\mathrm{Cdc} 42$, Rac1 and Rap1. GGTase-II facilitates prenylation of

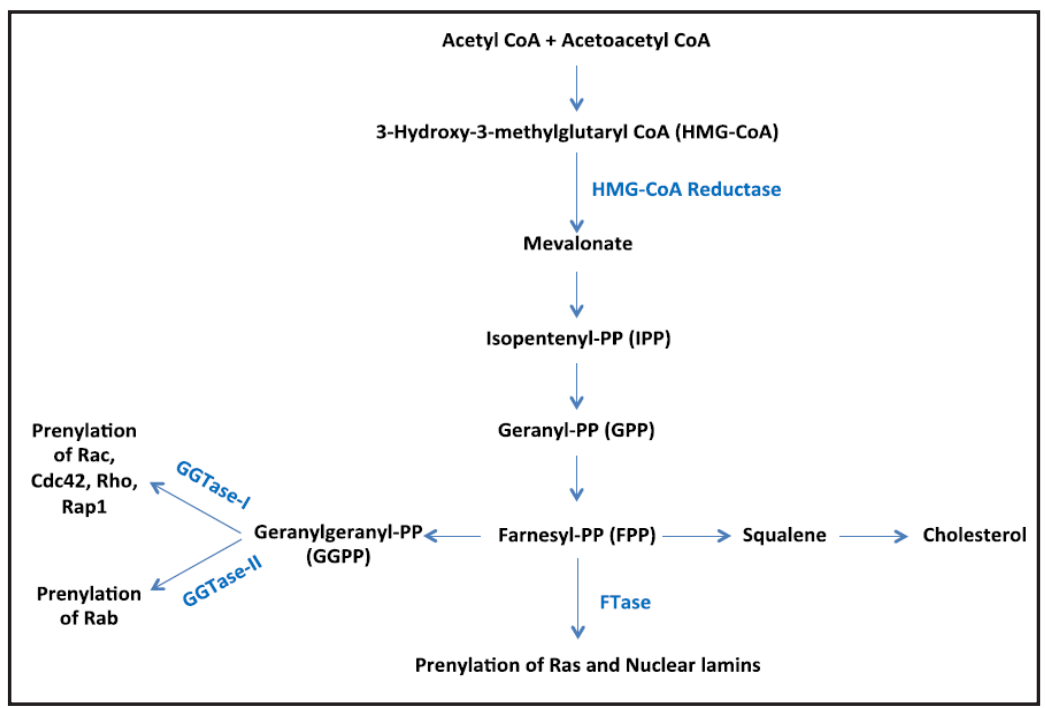
Rab subfamily of G-proteins. Both GGTase- I and GGTase- II utilize GGpp to geranylgeranylate the candidate G-proteins. Numerous studies from our laboratory have characterized these enzymes in the islet $\beta$-cell in relation to their roles in various cellular events including vesicular transport, cytoskeletal remodeling, proliferation and insulin secretion $[1,2,5,6,10,33]$.

on these observations, we concluded that caspase-3 mediates FTase/GGTase- $\alpha$ degradation in pancreatic $\beta$-cells under conditions of cellular apoptosis [14].

The current study is aimed at understanding the functional status of protein prenylation pathway in pancreatic $\beta$-cells exposed to a variety of metabolic stress conditions [glucotoxicity, lipotoxicity and ER-stress]. Our findings not only provide the first evidence indicating caspase- 3 activation and FTase/GGTase- $\alpha$ degradation; they also demonstrate significant attenuation of FTase and GGTase activities resulting in accumulation of unprenylated proteins.

\section{Materials and Methods}

\section{Materials}

Antisera against cleaved caspase-3 [active form] was from Cell Signaling [Danvers, MA]. Monoclonal anti $\beta$-actin antibody was from Sigma Chemical Company (St. Louis, MO). The antiserum against the FTase/ GGTase- $\alpha$ subunit was from Santa Cruz Biotechnology, Inc. [Santa Cruz, CA]. Anti-mouse or anti-rabbit IgG-horseradish peroxidase conjugates and ECL kits were from Amersham Biosciences [Piscataway, NJ]. Tritiated farnesyl pyrophosphate $\left(\left[{ }^{3} \mathrm{H}\right] \mathrm{Fpp} ; \mathrm{NET} 1042 ; 50 \mu \mathrm{Ci} / 0.1 \mathrm{ml}\right)$ and geranylgeranyl pyrophosphate $\left(\left[{ }^{3} \mathrm{H}\right] \mathrm{GGpp}\right.$; NET 1052; $50 \mu \mathrm{Ci} / 0.1 \mathrm{ml}$ ) were from PerkinElmer/NEN [Waltham, MA]. Ras-Cys-Val-Lys-Ser protein and Ras CVLL [Rho analog] proteins were from Calbiochem/EMD [Gibbstown, NJ]. Bicinchoninic Acid Assay [BCA] was from Pierce-Thermo-Fisher [Waltham, MA].

INS-1 832/13 cells, islets from a human donor, and Zucker lean control and Zucker diabetic fatty rats: Cell culture and treatments

INS-1 832/13 cells were cultured in RPMI-1640 medium containing $10 \%$ heat-inactivated fetal bovine serum supplemented with $100 \mathrm{IU} / \mathrm{ml}$ penicillin and $100 \mathrm{IU} / \mathrm{ml}$ streptomycin, $1 \mathrm{mM}$ sodium pyruvate, $50 \mu \mathrm{M}$ 2-mercaptoethanol, and $10 \mathrm{mM}$ HEPES [pH 7.4]. The medium was changed twice, and cells were subcloned weekly. Islets were isolated from normal Sprague-Dawley rats, ZDF rats and their age-matched lean controls by the collagenase digestion method $[2,8,9,15]$. All protocols, including isolation of pancreatic islets from rats, were reviewed and approved by our Institutional Animal Care and Use Committee. Human islets were from Prodo Laboratories, Inc. (Irvine, CA). Islets used in this study [90\% pure and $95 \%$ viable] were from a 30 year old Caucasian male [133 kg; BMI of 34.1; no history of diabetes; and HbA1c is 5.4\%]. Following 


\section{Cellular Physiology Cell Physiol Biochem 2016;39:2110-2120 and BiOChemistry \begin{tabular}{l|l} 
DOI: 10.1159/000447907 & $\begin{array}{l}\text { C } 2016 \text { The Author(s). Published by S. Karger AG, Basel } \\
\text { www.karger.com/cpb }\end{array}$
\end{tabular} \\ Veluthakal et al.: Metabolic Stress Inactivates Prenyltransferases in Islet $\beta$-Cells}

incubation in the islet culture medium [provided by Prodo Laboratories] in the presence of low (5.8 $\mathrm{mM})$ or high $(30 \mathrm{mM})$ glucose, islets were homogenized in RIPA buffer and used for Western blotting.

\section{Western blotting}

Proteins from INS-1 832/13 cells or rat islets were separated by SDS-PAGE on $10 \%$ [w/v] polyacrylamide mini gels and electrotransferred to nitrocellulose membrane. The membranes were blocked with 5\% non-fat dry milk in TBS-T [10 mM Tris- $\mathrm{HCl}$; pH 7.4], 8.8 g/liter NaCl, and 0.1\% Tween 20] for $2 \mathrm{~h}$ at room temperature. The membranes were then incubated overnight at $4{ }^{\circ} \mathrm{C}$ with antisera raised against the cleaved [active fragment] caspase-3 [1:250] or FTase/GGTase- $\alpha$ subunit [1:400) in TBS-T containing 5\% BSA. The membranes were washed 5 times for 5 min each with TBS-T and probed with appropriate horseradish peroxidase-conjugated secondary antibodies in 5\% non-fat dry milk in TBS-T at room temperature for 1 h. After washing, the immune complexes comprising of the target proteins were detected using the ECL kit. The membranes then were stripped and reprobed with $\beta$-actin. The band intensity was quantified and protein expression levels were calculated relative to $\beta$-actin in the same sample.

FTase and GGTase Assays

These assays were performed using a modified method as we described in [16]. Briefly, INS-1 $832 / 13$ cells were treated with low [5 $\mathrm{mM}]$ or high $[25 \mathrm{mM}$ ] glucose for times indicated in the text. Stock solutions of palmitate [PA] were prepared as described [17], and cells were incubated with $0.3 \mathrm{mM}$ PA for $24 \mathrm{hr}$ [lipotoxicity model]. INS-1 832/13 cells were cultured in the absence or presence of thapsigargin [Tg; $0.25 \mu \mathrm{M}$ ], a known inducer of ER-stress for different intervals as described in the text. Subsequently, cells were lysed in $500 \mu \mathrm{l}$ of buffer [150 mM NaCl, $5 \mathrm{mM} \mathrm{MgCl}, 1 \mathrm{mM}$ phenylmethylsulfonyl fluoride, 1 $\mathrm{mM}$ dithiothreitol, $1 \mathrm{mM}$ sodium vanadate, $1 \mathrm{mM}$ sodium phosphate, 1\% Triton X-100, 0.05\% SDS, $10 \mu \mathrm{g} /$ $\mathrm{ml}$ aprotinin, $10 \mu \mathrm{g} / \mathrm{ml}$ leupeptin, $50 \mathrm{mM}$ HEPES, pH 7.5]. Crude lysates were sonicated and centrifuged $10,000 \mathrm{~g}$. Protein concentration was determined in cleared lysates using the bicinchoninic acid assay. The in vitro filtration assay was initiated by adding a $5-\mu \mathrm{l}$ aliquot of diluted and normalized extract to $45 \mu \mathrm{l}$ of reaction assay solution [5 $\mathrm{mM} \mathrm{MgCl}_{2}, 5 \mathrm{mM}$ dithiothreitol, $100 \mathrm{nM}$ Ras or Rho protein, $100 \mathrm{nM}\left[{ }^{3} \mathrm{H}\right]$-Fpp- or [ $\left.{ }^{3} \mathrm{H}\right]$-GGpp [20 mCi/mmol, $50 \mathrm{mM}$ HEPES, pH 7.5] and incubated for 30 minutes. The reaction was stopped using $1 \mathrm{ml}$ of ice-cold $1 \mathrm{M} \mathrm{HCl}$ in ethanol and samples were placed on ice for $15 \mathrm{~min}$. The reaction mixtures were individually filtered through Whatman GF/C glass-fiber filters, air dried and placed in scintillation fluid and quantified by scintillation spectrometry.

\section{Statistical analysis}

Results are expressed as means with their standard errors as indicated. Data are analyzed using one way ANOVA followed by Bonferroni posthoc test [GraphPad Prism 5; GraphPad Software, Inc., La Jolla, CA, USA]. Differences between control and treatment groups were considered significant if $p$ is $<0.05$.

\section{Results}

Using pharmacological and molecular biological approaches, we have previously demonstrated requisite roles for protein farnesylation and geranylgeranylation in GSIS in INS-1 832/13 $\beta$-cells and normal rodent islets $[1,2,5,6,8-11]$. Key findings were also confirmed in islets from normal human donors. However, significant gaps still exist in our current understanding about the metabolic fate of these pathways under the duress of metabolic stress, including glucotoxicity, lipotoxicity and ER stress in the islet $\beta$-cell $[6,15$, $18,19]$. Therefore, we undertook the current investigation to assess the functional status of FTase/GGTase- $\alpha$ signaling mechanisms in INS-1 832/13 cells, normal rodent and human islets exposed to gluco-, lipotoxic and ER stress conditions.

Metabolic stress conditions activate caspase-3 and induce degradation of FTase/GGTase- $\alpha$ in a variety of insulin secreting cells

Data depicted in Fig. 2 [Panel A] indicate significant activation of caspase-3 and cleavage of FTase/GGTase- $\alpha$ in INS-1 832/13 cells exposed to gluco- and lipotoxic conditions. Pooled 
Fig. 2. Glucotoxic, lipotoxic or ER stress conditions promote caspase -3 activation and FTase/GGTase- $\alpha$ degradation in a variety of insulin-secreting cells. Panel A: INS-1 832/13 cells were incubated with low glucose [LG; $2.5 \mathrm{mM}$ ], high glucose [HG; $25 \mathrm{mM}$ ] or palmitate [PA; $0.3 \mathrm{mM}$ ] as indicated in the text. Caspase-3 activation and FTase/GGTase- $\alpha$ degradation were quantified by Western blotting method. * represents $\mathrm{p}<0.05$ vs. LG. Pooled data from three experiments are provided in Panels B and C. HG-mediated caspase- 3 activation and FTase/GGTase- $\alpha$ degradation were also determined in human islets (Panel D). These findings were replicated in islets derived from ZDF rat [Panel E; 13 weeks]. Incubation of INS 1-832/13 cells with thapsigargin $\quad[\mathrm{Tg} ; \quad 0.25 \mu \mathrm{M}$; 6-24 h], a known inducer of ER stress, significantly increased caspase- 3 activation and FTase/ GGTase- $\alpha$ degradation in INS$1832 / 13$ cells (Panel F) and normal rat islets $(24 \mathrm{~h}$; Panel G). Data are representative of 2-3 experiments.

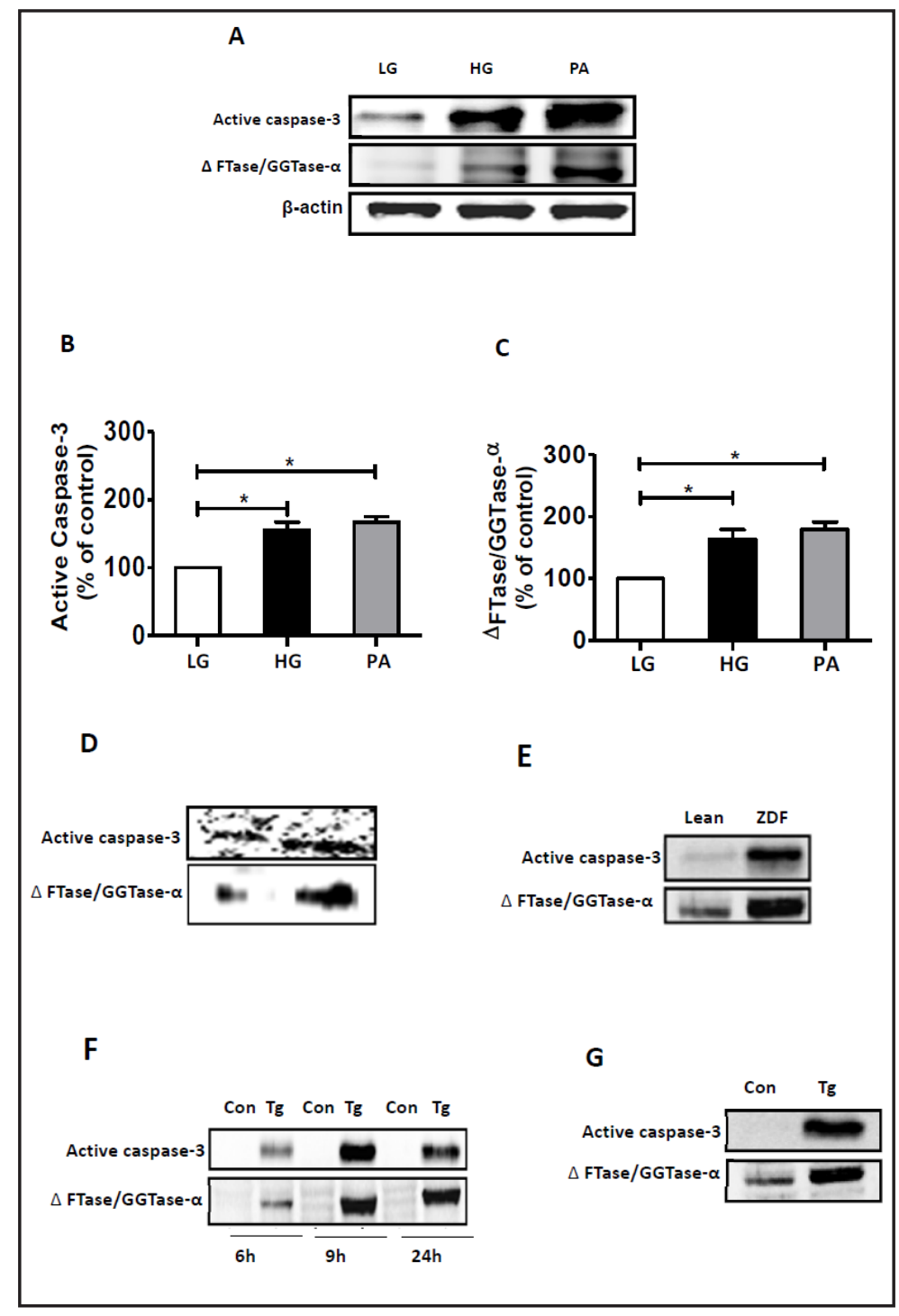

data from multiple experiments for caspase- 3 activation and FTase/GGTase- $\alpha$ degradation are provided in Panels B and C, respectively. Compatible with these observations, we detected caspase-3 activation and FTase/GGTase- $\alpha$ degradation in human islets incubated under glucotoxic conditions [Panel D]. It is noteworthy that caspase-3 activation and degradation of FTase/GGTase- $\alpha$ were also seen in islet derived from the [ZDF] rat, a model for Type 2 diabetes [Panel E]. Lastly, forced induction of ER-stress in INS-1 832/13 cells following incubation with thapsigargin [Tg], a known inducer of ER-stress, markedly increased caspase- 3 activity and FTase/GGTase- $\alpha$ degradation in a time-dependent fashion. Such an effect of Tg was demonstrable in these cells as early as $6 \mathrm{hr}$ of exposure to Tg [Panel F]. We replicated these observations in normal rodent islets as well [Panel G]. Together, these data demonstrate activation of caspase- 3 and degradation of FTase/GGTase- $\alpha$ in INS-1 832/13 cells, rat islets and human islets exposed to a wide variety of metabolic stress conditions. Lastly, such metabolic defects were also demonstrable in islets from the ZDF rat.

Metabolic stress conditions induce defects in FTase and GGTase activities in INS-1 832/13 cells

We next examined consequences of FTase/GGTase- $\alpha$ degradation on the catalytic activities of FTase and GGTase-I in INS-1 832/13 cells exposed to glucotoxic, lipotoxic and 
Fig. 3. Glucotoxic, lipotoxic or ER stress conditions markedly attenuate FTase and GGTase activities in INS-1 832/13 cells. FTase and GGTase activities are measured using $\left[{ }^{3} \mathrm{H}\right]$-Fpp- or $\left[{ }^{3} \mathrm{H}\right]$-GGpp, respectively [16]. LG [open bar], HG [dark bar], PA [dark filled] and Tg [light filled]. Data are mean \pm SEM from 5 determinations in each case. * represents $\mathrm{p}<0.05$ vs LG.
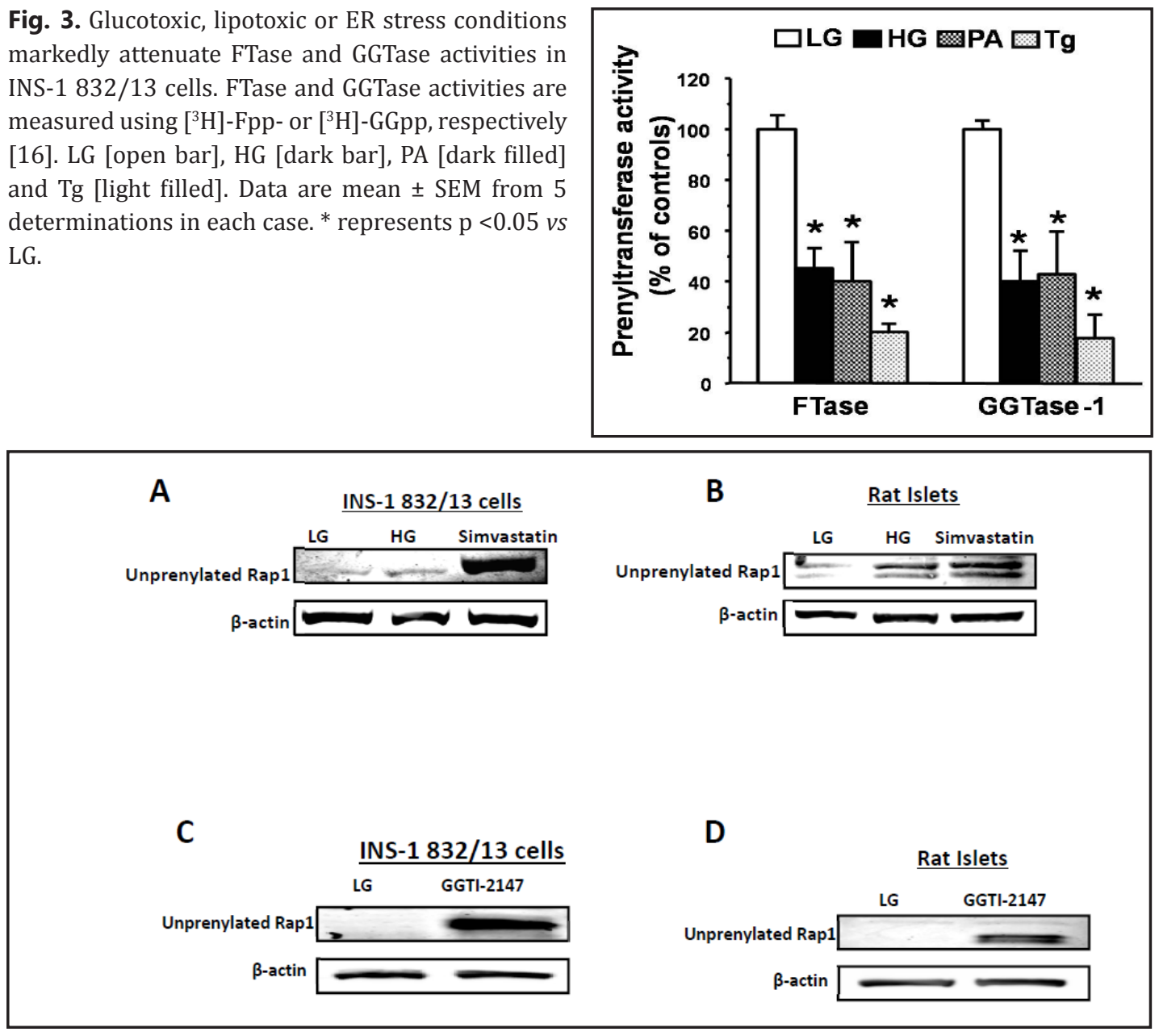

Fig. 4. HG, Simvastatin [an inhibitor of MVA biosynthesis; Fig. 1] or GGTI-2147 [an inhibitor of GGTase -I] markedly induce accumulation of unprenylated Rap1 in INS-1 832/13 cells and normal rat islets. INS-1 832/13 cells (Panel A) and normal rat islets (Panel B) were incubated with LG, HG or Simvastatin [15 $\mu \mathrm{M}$ ] for $24 \mathrm{~h}$. Relative abundance of unprenylated Rap1 was determined by Western blotting. Blots were probed for $\beta$-actin as a loading control. Representative blots from two experiments are shown here. In addition, INS-1 832/13 cells (Panel C) and normal rat islets (Panel D) were incubated with LG, or GGTI-2147 (20 $\mu \mathrm{M}$ ) for $24 \mathrm{~h}$. Relative abundance of unprenylated Rap1 was determined by Western blotting. Blots were probed for $\beta$-actin as a loading control. Representative blots from two experiments are shown here. As stated in the text, numerous recent studies including our own, have demonstrated significant reduction in GSIS in insulin-secreting cells exposed to HG or Simvastatin [1, 24-29].

ER stress conditions. Data shown in Fig. 3 demonstrate a significant reduction in both FTase and GGTase activities under conditions in which the FTase/GGTase- $\alpha$ is degraded (Fig. 2). We recently determined the specificity of caspase-3 mediated degradation of FTase/GGTase- $\alpha$ using specific inhibitor of caspase-3 and recombinant biologically-active caspase-3 [14]. Based on these data we conclude that metabolic stress conditions promote activation of caspase- 3 leading to degradation of FTase/GGTase- $\alpha$ culminating in the catalytic inactivation of FTase and GGTase.

Inhibition of protein prenyltransferases results in accumulation of unprenylated proteins in INS-1 832/13 cells and normal rat islets

As a logical extension to the above studies, we asked if functional inactivation of prenyltransferases results in accumulation of unprenylated G-proteins in pancreatic KARGER 


\section{Cellular Physiology Cell Physiol Biochem 2016;39:2110-2120 \begin{tabular}{ll|l} 
DOI: 10.1159/000447907 & $\begin{array}{l}\text { O 2016 The Author(s). Published by S. Karger AG, Basel } \\
\text { www.karger.com/cpb }\end{array}$
\end{tabular} \\ Veluthakal et al.: Metabolic Stress Inactivates Prenyltransferases in Islet $\beta$-Cells}

$\beta$-cells exposed to glucotoxic conditions. In these studies we also examined the effects of Simvastatin, a known inhibitor of HMG-CoA reductase pathway, which depletes intracellular pools of MVA and its downstream metabolites [Fpp and GGpp], which are required for protein prenylation by FTase and GGTase (Fig. 1). In order to identify the abundance of unprenylated proteins, we used an antiserum directed against unprenylated Rap1, which is prenylated by GGTase-I (Fig. 1). Data in Fig. 4 indicate increased accumulation of Rap1 in INS-1 832/13 cells [Panel A] and normal rat islets [Panel B] exposed to glucotoxic conditions. As expected, inhibition of biosynthesis of Fpp and GGpp with Simvastatin also resulted in accumulation of unprenylated Rap1 in INS-1 832/13 cells [Panel A] and normal rat islets (Panel B). To further validate our model, in an alternate approach, we asked if direct inhibition of GGTase-I with a small molecule inhibitor [GGTI-2147] leads to accumulation of unprenylated Rap1 in pancreatic $\beta$-cells. Data in Fig. 4 demonstrate that treatment of INS-1 832/13 cells with GGTI-2147 cells leads to accumulation of unprenylated Rap1 in INS-1 832/13 cells [Panel C] and normal rat islets [Panel D]. Based on these data we propose that metabolic stress conditions induce caspase- 3 mediated degradation of FTase/GGTase- $\alpha$ leading to functional inactivation of prenyltransferases and accumulation of unprenylated proteins in pancreatic $\beta$-cells. Such a formulation was affirmed via the use pharmacological inhibitors of Fpp and GGpp biosynthesis [Simvastatin] and GGTase-I [GGTI-2147]. Together, our findings suggest that caspase- 3 mediated degradation and functional inactivation of FTase and GGTase culminates in loss in cell viability in pancreatic $\beta$-cells under the duress of metabolic stress conditions, including glucotoxicity [see below].

\section{Discussion}

Emerging evidence from multiple laboratories suggests requisite regulatory roles for protein prenylation in a variety of cellular processes including growth, differentiation, cytoskeletal organization and dynamics and vesicle trafficking [3-7]. It is also becoming increasingly clear that alterations in prenylation of proteins [Ras, nuclear lamins] lead to human pathologies including cancer; neurodegenerative diseases, retinitis pigmentosa, and premature ageing syndromes [20-23]. The overall objective of our study was to assess the functional status of protein prenylation signaling in pancreatic $\beta$-cells exposed to metabolic stress conditions. In these studies, we employed INS-1 832/13 cells, normal rat islets, human islets and islets from the ZDF rat, a model for Type 2 diabetes. We demonstrated that metabolic stress activates caspase- 3 and induces degradation of FTase/GGTase- $\alpha$ in a variety of insulin secreting cells leading to functional defects [inactivation] in FTase and GGTase activities. We also observed that, in a manner akin to the effects seen under glucotoxic conditions, inhibition of intracellular generation of Fpp or GGpp (with Simvastatin; Fig. 1) as well as inhibition of GGTase-I activity (GGTI-2147; Fig. 1) results in accumulation of unprenylated G-proteins. In support of our current findings and conclusions, are earlier studies, which demonstrated significant reduction in GSIS in insulin-secreting cells exposed to HG or Simvastatin [1, 24-29]. Together, our findings suggest that islet $\beta$-cell dysfunction [e.g., loss in GSIS] under metabolic stress conditions may, in part, be due to defects in the protein prenylation signaling that we demonstrated in the current study.

The current studies provide the first evidence to suggest significant defects in FTase and GGTase activities in pancreatic $\beta$-cells following exposure to gluco-, lipotoxic and ER stress conditions. We propose that it is consequential to the degradation of the FTase/GGTase- $\alpha$ subunit under these conditions. Cleavage of FTase/GGTase- $\alpha$ subunit could result in the defects in the formation of the heterodimer [ $\alpha \beta$ subunit complex] of the enzyme leading to its functional inactivation. It should be noted that the $\alpha$-subunit of FTase/GGTase is considered the regulatory subunit while the $\beta$ subunit contains the catalytic active site. Interestingly, the $\beta$ subunit is functionally inactive without $\alpha$ subunit suggesting that the heterodimeric "holoenzyme" conformation is necessary for the catalytic function of the enzyme. 
Fig. 5. Proposed model highlighting potential mechanisms underlying metabolic stress induced $\beta$-cell dysfunction under glucotoxic, lipotoxic and ER-stress conditions. Based on the data accrued in the current investigation and published evidence in the literature, we propose that glucotoxic, lipotoxic or ER-stress conditions induce mitochondrial dysregulation of the islet $\beta$-cell leading to caspase- 3 activation. Some of these underlying mechanisms could include generation of excessive reactive oxygen species [oxidative stress] mediated by phagocyte-like NADPH oxidase [Nox2], which, in turn, leads to activation of stress kinases [p38MAPK; JNK1/2] and downstream signaling steps $[6,15,17,26]$. Activated caspase- 3 facilitates cleavage of the FTase/GGTase $\alpha$-subunit culminating in defective prenylation and accumulation of unprenylated G-proteins. Potential regulatory roles of unprenylated proteins in the onset of islet dysfunction remains to be investigated. Further, studies along the lines to address the regulatory roles of the "degraded fragment" of FTase/ GGTase- $\alpha$ in the induction of defective insulin secretion and loss in $\beta$-cell survival should yield novel insights into mechanisms underlying islet dysfunction under metabolic stress and diabetes.

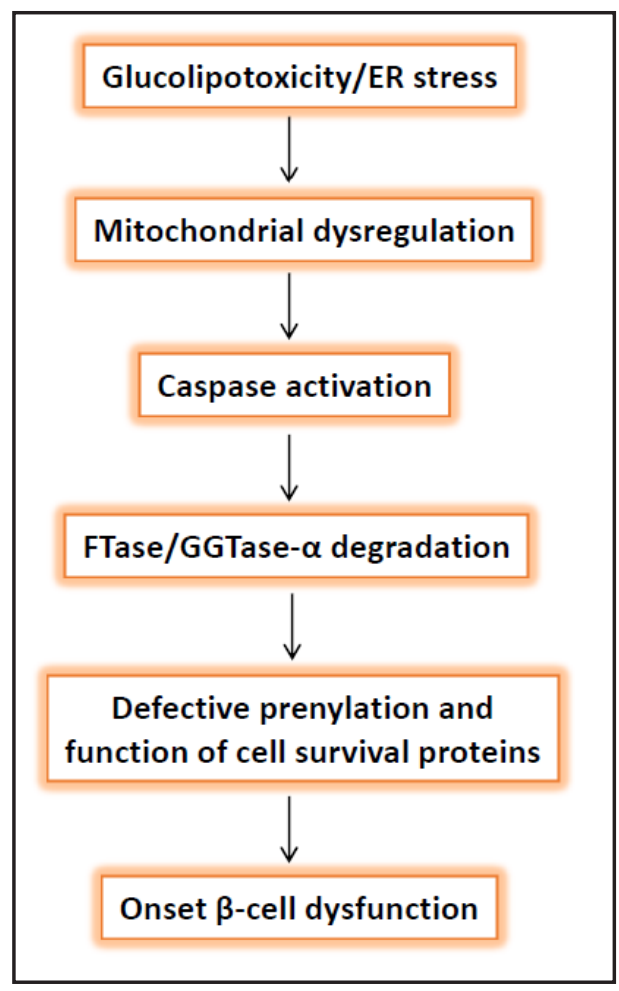

What then are potential functional consequences of impaired prenylation of proteins? Recently Khan et al. have reported hyperactivation of macrophages and associated induction of erosive arthritis in mice lacking GGTase-I [30], thus raising potential for regulatory roles of geranylgeranylation in inflammatory cell signaling [30,31]. Interestingly, high levels of active [GTP-bound] Rac1, Cdc42 and RhoA were seen in GGTase-deficient cells suggesting potential alternate mechanisms for the activation of these unprenylated G-proteins. They also reported activation of p38 and NF- $\mathrm{KB}$ and enhanced production of proinflammatory cytokines consequential to GGTase-I deficiency [30]. Along these lines, studies by Dunford and associates have suggested that inhibition of protein prenylation by nitrogen-containing bisphosphonates caused paradoxical and sustained activation of Rac, Cdc42 and Rho G-proteins in J774 macrophages [32]. Compatible with these findings is recently published evidence from our laboratory suggesting sustained activation of Rac1, a geranylgeranylated protein, in $\beta$-cell models of glucolipotoxicity, ER stress and diabetes $[6,15,17,19,33]$. We also observed hyperactivation of Rac1 in human islets exposed to glucotoxic conditions and in islets derived from the ZDF rat [15]. These findings have led us to propose that Rac1 plays both positive and negative modulatory roles in the regulation of $\beta$-cell function in the sense that while it is critical for GSIS, Rac1 also exerts damaging roles under pathological conditions by inducing Nox 2 activity to create excessive oxidative stress, mitochondrial damage and cell demise $[15,26,34]$. It is noteworthy that, recent studies from our laboratories have demonstrated sustained activation of Rac1 in retina from animal models of diabetes [35], thus suggesting systemic effects of diabetic conditions in the sustained activation of Rac 1 and associated increase in Nox2-derived oxidative stress leading to cell dysregulation in target tissues. Together, these findings demonstrate constitutive activation of specific G-proteins under various pathological conditions in the absence of requisite prenylation. Future studies will need to identify the "prenylation-independent" regulatory mechanisms that underlie G-protein activation and potential alterations in their subcellular trafficking [mis-targeting] of these proteins, if any, under the conditions of metabolic stress.

Recent studies have also demonstrated roles of protein prenylation mediated by FTase, GGTase-I and GGTase-II in islet $\beta$-cell function including GSIS [5, 6, 10-12]. Even though our current findings suggest significant defects in islet $\beta$-cell induced by metabolic stress, KARGER 


\section{Cellular Physiology Cell Physiol Biochem 2016;39:2110-2120

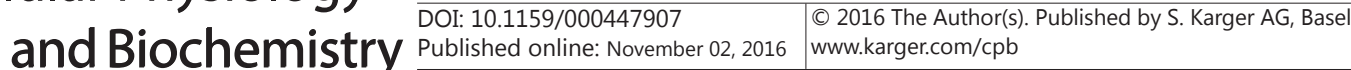 \\ Veluthakal et al.: Metabolic Stress Inactivates Prenyltransferases in Islet $\beta$-Cells}

specifically at the level of degradation of the regulatory FTase/GGTase- $\alpha$ subunit, it is likely that defects in protein prenylation might be occurring at other "arms" of the protein prenylation pathway (Fig. 1). In this context, elegant studies by Jiang and associates [36] demonstrated requisite roles for granylgeranyl pyrophosphate synthase [GGPPS] in islet function in health and diabetes. This enzyme is responsible for intracellular generation of GGpp (Fig. 1). Using a variety of in vitro and in vivo approaches, these researchers demonstrated critical roles for GGPPS in islet $\beta$-cell function during the onset of diabetes. Functional activation of GGPPS in islets from $d b / d b$ mice is increased during the initial compensatory period, followed by a sharp decline during the onset of insulin secretory abnormality. Furthermore, conditional deletion of GGPPS in the islet $\beta$-cell resulted in depletion of intracellular GGpp and membrane targeting of Rab27A, and reduced the number of insulin granules in the proximity of the plasma membrane. These data suggest significant defects in granule docking in GGPPS-null mice, leading to decreased GSIS. As highlighted recently in [37], it is expected that the studies by Jiang et al. [36] will form the basis for future investigations in the field, which might fill the knowledge gaps in our current understanding of the regulatory roles of G-proteins in islet biology in health and diabetes.

Based on the data accrued from our current study, we propose a model for induction of defects in the protein prenylation pathway in islet $\beta$-cells exposed to metabolic stress (Fig. 5). Metabolic stress induces mitochondrial dysregulation and caspase activation; such effects may, in part, be due to increased Nox2-mediated oxidative stress as we reported recently in [15]. Caspase- 3 activation leads to cleavage of the regulatory $\alpha$-subunit of FTase/GGTase resulting in functional inactivation of FTase and GGTase and consequential accumulation of unprenylated proteins. We have demonstrated sustained activation of Rac1 $[6,15,17,33]$, stress kinase [p38MAPK, JNK1/2; ref. 15, 26] and loss in GSIS [24-26] under these conditions in a variety of insulin-secreting cells. Additional studies are needed to further assess the functional status of other G-proteins, which have been implicated in islet survival and function, including GSIS. These investigations are underway in our laboratories currently.

\section{Abbreviations}

ER-stress (endoplasmic reticulum stress); Fpp (farnesylpyrophosphate); FTase (farnesyltransferase); FTase/GGTase- $\alpha$ ( $\alpha$-subunit of farnesyl- and geranylgeranyltransferase); GGTase (geranylgeranyltransferase); GGTI-2147 (geranylgeranyltransferase inhibitor-2147); GGpp (geranylgeranylpyrophosphate); GGPPS (geranylgeranylpyrophosphate synthase); GSIS (glucose-stimulated insulin secretion); MVA (mevalonic acid).

\section{Acknowledgments}

This study was supported in part by grants from the Department of Veterans Affairs (1I01BX002801 to AK), the National Institutes of Health (EY014370, EY017313 and EY022230 to RAK; DK74921 and EY022230 to AK), the Juvenile Diabetes Research Foundation (52012-313 to RAK; and 5-2012-257 to AK), and an unrestricted grant to the Ophthalmology Department from Research to Prevent Blindness. AK is the recipient of a Senior Research Career Scientist Award from the Department of Veterans Affairs (13S-RCS-006). MLG is supported by a Merit grant from the Department of VA [1 I01 BX002019-01A2]. The authors thank Prof. Chris Newgard for INS-1 832/13 cells. Also, the authors would like to express their sincere thanks to Drs. Vaibhav Sidarala and Anil Chekuri for assistance in these studies.

\section{Disclosure Statement}

None.

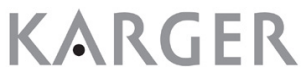




\section{Cellular Physiology Cell Physiol Biochem 2016;39:2110-2120 and Biochemistry \begin{tabular}{l|l} 
DOI: 10.1159/000447907 & (c) 2016 The Author(s). Published by S. Karger AG, Basel \\
www.karger.com/cpb
\end{tabular} \\ Veluthakal et al.: Metabolic Stress Inactivates Prenyltransferases in Islet $\beta$-Cells}

\section{References}

1 Metz SA, Rabaglia ME, Stock JB, Kowluru A: Modulation of insulin secretion from normal rat islets by inhibitors of the post-translational modifications of GTP-binding proteins. Biochem J 1993;295:31-40.

2 Kowluru A, Seavey SE, Li G, Sorenson RL, Weinhaus AJ, Nesher R, Rabaglia ME, Vadakekalam J, Metz SA: Glucose- and GTP-dependent stimulation of the carboxyl methylation of CDC42 in rodent and human pancreatic islets and pure beta cells. Evidence for an essential role of GTP-binding proteins in nutrientinduced insulin secretion. J Clin Invest 1996;98:540-555.

3 Lane KT, Beese LS: Thematic review series: lipid posttranslational modifications. Structural biology of protein farnesyltransferase and geranylgeranyltransferase type I. J Lipid Res 2006;47:681-699.

4 McTaggart SJ: Isoprenylated proteins. Cell Mol Life Sci 2006;63:255-267

5 Kowluru A: Protein prenylation in glucose-induced insulin secretion from the pancreatic islet beta cell: a perspective. J Cell and Molecul Med 2008;12:164-173.

6 Kowluru A: Small G proteins in islet beta-cell function. Endocr Rev 2010;31:52-78.

7 Wang M, Casey PJ: Protein prenylation: unique fats make their mark on biology. Nat Rev. Mol Cell Biol 2016;17:110-122.

8 Kowluru A, Li G, Rabaglia ME, Segu VB, Hofmann F, Aktories K, Metz SA: Evidence for differential roles of the Rho subfamily of GTP-binding proteins in glucose- and calcium-induced insulin secretion from pancreatic beta cells. Biochem Pharmacol 1997;54:1097-1108.

9 Veluthakal R, Kaur H, Goalstone M, Kowluru A: Dominant-negative alpha-subunit of farnesyl- and geranyltransferase inhibits glucose-stimulated, but not KCl-stimulated, insulin secretion in INS 832/13 cells. Diabetes 2007;56:204-210.

10 Kowluru A, Veluthakal R, Rhodes CJ, Kamath V, Syed I, Koch BJ: Protein farnesylation-dependent Raf/ extracellular signal-related kinase signaling links to cytoskeletal remodeling to facilitate glucose-induced insulin secretion in pancreatic beta-cells. Diabetes 2010;59:967-977.

11 Matti A, Kyathanahalli C, Kowluru A: Protein farnesylation is requisite for mitochondrial fuel-induced insulin release: Further evidence to link reactive oxygen species generation to insulin secretion in pancreatic beta-cells. Islets 2012;4:74-77.

12 Arora D, Syed I, Machhadieh B, McKenna C, Kowluru A: Rab-geranylgeranyl transferase regulates glucosestimulated insulin secretion from pancreatic beta cells. Islets 2012;4:354-358.

13 Kim KW, Chung HH, Chung CW, Kim IK, Miura M, Wang S, Zhu H, Moon KD, Rha GB, Park JH, Jo DG, Woo HN, Song YH, Kim BJ, Yuan J, Jung YK: Inactivation of farnesyltransferase and geranylgeranyltransferase I by caspase-3: cleavage of the common alpha subunit during apoptosis. Oncogene 2001;20:358-366.

14 Arora DK, Mohammed AM, Kowluru A: Nifedipine prevents etoposide-induced caspase-3 activation, prenyl transferase degradation and loss in cell viability in pancreatic beta-cells. Apoptosis 2013;18:1-8.

15 Syed I, Kyathanahalli CN, Jayaram B, Govind S, Rhodes CJ, Kowluru RA, Kowluru A: Increased phagocytelike NADPH oxidase and ROS generation in type 2 diabetic ZDF rat and human islets: role of Rac1-JNK1/2 signaling pathway in mitochondrial dysregulation in the diabetic islet. Diabetes 2011;60:2843-2852.

16 Goalstone M, Kamath V, Kowluru A: Glucose activates prenyltransferases in pancreatic islet beta-cells. Biochem Biophys Res Commun 2010;391:895-898.

17 Syed I, Jayaram B, Subasinghe W, Kowluru A: Tiam1/Rac1 signaling pathway mediates palmitate-induced, ceramide-sensitive generation of superoxides and lipid peroxides and the loss of mitochondrial membrane potential in pancreatic beta-cells. Biochem Pharmacol 2010;80:874-883.

18 Gehrmann W, Würdemann W, Plötz T, Jörns A, Lenzen S, Elsner M. Antagonism Between Saturated and Unsaturated Fatty Acids in ROS Mediated Lipotoxicity in Rat Insulin-Producing Cells. Cell Physiol Biochem 2015;36:852-865.

19 Zhou S, Yu D, Ning S, Zhang H, Jiang L, He L, Li M, Sun M. Augmented Rac1 Expression and Activity are Associated with Oxidative Stress and Decline of $\beta$ Cell Function in Obesity. Cell Physiol Biochem 2015;35:2135-2148.

20 Agrawal AG, Somani RR: Farnesyltransferase inhibitor as anticancer agent. Mini Rev Med Chem 2009;9:638-652.

21 Blum R, Kloog Y: Tailoring Ras-pathway--inhibitor combinations for cancer therapy. Drug Resist Update 2005;8:369-380.

22 Novelli G, D'Apice MR: Protein farnesylation and disease. J Inherit Metab Dis 2012; 35: 917-926. 


\section{Cellular Physiology Cell Physiol Biochem 2016;39:2110-2120 \begin{tabular}{ll|l} 
DOI: 10.1159/000447907 & O 2016 The Author(s). Published by S. Karger AG, Basel \\
and Biochemistryer.com/cpb
\end{tabular} \\ Veluthakal et al.: Metabolic Stress Inactivates Prenyltransferases in Islet $\beta$-Cells}

23 Resh MD: Targeting protein lipidation in disease. Trends Mol Med 2012;18:206-214.

24 Khadija S, Veluthakal R, Sidarala V, Kowluru A. Glucotoxic and diabetic conditions induce caspase 6-mediated degradation of nuclear lamin A in human islets, rodent islets and INS-1 832/13 cells. Apoptosis 2014;19:1691-1701.

25 Arora DK, Machhadieh B, Matti A, Wadzinski BE, Ramanadham S, Kowluru A. High glucose exposure promotes activation of protein phosphatase $2 \mathrm{~A}$ in rodent islets and INS-1 832/13 $\beta$-cells by increasing the posttranslational carboxylmethylation of its catalytic subunit. Endocrinology 2014;155:380-391.

26 Sidarala V, Veluthakal R, Syeda K, Vlaar C, Newsholme P, Kowluru A: Phagocyte-like NADPH oxidase (Nox2) promotes activation of p38MAPK in pancreatic $\beta$-cells under glucotoxic conditions: evidence for a requisite role for Ras-related C3 botulinum toxin substrate 1 (Rac1). Biochem Pharmacol 2015;95:301-310.

27 Yaluri N, Modi S, Lopez Rodriguez M, Stancakova A, Kuusisto J, Kokkola T, Laakso M. Simvastatin impairs insulin secretion by multiple mechanisms in MIN6 cells. PloS One 2015;10:1-20.

28 Ishikawa M, Okajima F, Inoue N, Motomura K, Kato T, Takahashi A, Oikawa S, Yamada N, Shimano H. Distinct effects of pravastatin, atrovastatin, and simvastatin on insulin secretion from beta-cell line, MIN6 cells. J Atheroscler Thromb 2006;13:329-335.

29 Yada T, Nakata M, Shiraishi T, Kakei M. Inhibition by simvastatin, but not parvastatin, of glucose-induced cytosolic Ca2 + signaling and insulin secretion due to blockade of L-type Ca2+ channels in rat islet betacells. Br J Pharmacol 1999;126:1205-1213.

30 Khan OM, Ibrahim MX, Jonsson IM, Karlsson C, Liu M, Sjogren AK, Olofsson FJ, Brisslert M, Andersson S, Ohlsson C, Hulten LM, Bokarewa M, Bergo MO: Geranylgeranyl-transferase type I (GGTase-I) deficiency hyperactivates macrophages and induces erosive arthritis in mice. J Clin Invest 2011;121:628-639.

31 Philips MR: The perplexing case of the geranylgeranyl transferase-deficient mouse. J Clin Invest 2011;121:510-513.

32 Dunford JE, Rogers MJ, Ebetino FH, Phipps RJ, Coxon FP: Inhibition of protein prenylation by bisphosphonates causes sustained activation of Rac, Cdc42, and Rho GTPases. J Bone Miner Res 2006;21:684-694.

33 Kowluru A: Friendly, and not so friendly, roles of Rac1 in islet beta-cell function: lessons learnt from pharmacological and molecular biological approaches. Biochem Pharmacol 2011;81:965-975.

34 Kowluru A, Kowluru RA: Phagocyte-like NADPH oxidase [Nox2] in cellular dysfunction in models of glucolipotoxicity and diabetes. Biochem Pharmacol 2014;88:275-283.

35 Kowluru RA, Kowluru A, Veluthakal R, Mohannad G, Syed I, Santos JM, Mishra M: Tiam1-Rac1 siganling axis-mediated activation of NADPH oxidase-2 initiates mitochondrial damage in the development of diabetic retinopathy. Diabetologia 2014;57:1047-1056.

36 Jiang S, Shen D, Jia W-J, Han X, Shen N, Tao W, Gao X, Xue B, Li C-J. GGPPS-mediated Rab27A geranylgeranylation regulates beta-cell dysfunction during type 2 diabetes development by affecting insulin granule docked pool formation. J Pathol 2015;238:109-119.

37 Kowluru A: A lack of "glue" misplaces Rab27A to cause islet dysfunction in diabetes. J Pathol 2016;238:375377. 